\title{
Differences in Glomerular-Layer-Mediated Feedforward Inhibition onto Mitral and Tufted Cells Lead to Distinct Modes of Intensity Coding
}

\author{
Matthew Geramita and Nathan N. Urban \\ Department of Neurobiology, Center for Neuroscience at the University of Pittsburgh, Center for the Neural Basis of Cognition, University of Pittsburgh, \\ Pittsburgh, Pennsylvania 15213
}

Understanding how each of the many interneuron subtypes affects brain network activity is critical. In the mouse olfactory system, mitral cells (MCs) and tufted cells (TCs) comprise parallel pathways of olfactory bulb output that are thought to play distinct functional roles in odor coding. Here, in acute mouse olfactory bulb slices, we test how the two major classes of olfactory bulb interneurons differentially contribute to differences in MC versus TC response properties. We show that, whereas TCs respond to olfactory sensory neuron (OSN) stimulation with short latencies regardless of stimulation intensity, MC latencies correlate negatively with stimulation intensity. These differences between MCs and TCs are caused in part by weaker excitatory and stronger inhibitory currents onto MCs than onto TCs. These differences in inhibition between MCs and TCs are most pronounced during the first $150 \mathrm{~ms}$ after stimulation and are mediated by glomerular layer circuits. Therefore, blocking inhibition originating in the glomerular layer, but not granule-cell-mediated inhibition, reduces MC spike latency at weak stimulation intensities and distinct temporal patterns of odor-evoked responses in MCs and TCs emerge in part due to differences in glomerular-layer-mediated inhibition.

Key words: inhibition; olfaction; olfactory bulb

\section{Significance Statement}

Olfactory bulb mitral and tufted cells display different odor-evoked responses and are thought to form parallel channels of olfactory bulb output. Therefore, determining the circuit-level causes that drive these differences is vital. Here, we find that longer-latency responses in mitral cells, compared with tufted cells, are due to weaker excitation and stronger glomerular-layermediated inhibition.

\section{Introduction}

In multiple sensory systems, separate neuron types encode distinct features of sensory stimuli, yet olfaction has historically been viewed differently. Mitral cells (MCs) and tufted cells (TCs), the two principal types of neurons of the olfactory bulb, have been thought to play identical roles in odor coding despite clear anatomical differences (Mori et al., 1983; Orona et al., 1984; Igarashi et al., 2012). Recently, however, multiple studies have iden-

Received July 14, 2016; revised 0ct. 25, 2016; accepted Nov. 19, 2016.

Author contributions:M.G. and N.N.U. designed research;M.G. performed research;M.G. analyzed data;M.G. and N.N.U. wrote the paper.

This work was supported by the National Institute of Deafness and Other Communication Disorders-National Institutes of Health (Grant R01-DC011184 to N.N.U.). We thank Shawn Burton, Claire Cheetham, and members of the Urban laboratory for helpful comments and discussion and Greg LaRocca for excellent technical assistance.

The authors declare no competing financial interests.

Correspondence should be addressed to Nathan N. Urban, E1440 BSTWR, 200 Lothrop Street, University of Pittsburgh, Pittsburgh, PA 15213. E-mail: nurban@pitt.edu.

DOI:10.1523/JNEUROSCI.2245-16.2016

Copyright $\odot 2017$ the authors $\quad 0270-6474 / 17 / 371428-11 \$ 15.00 / 0$ tified functional differences between MCs and TCs that suggest that the olfactory system segregates olfactory information into parallel pathways, much like other sensory systems (Fukunaga et al., 2012; Igarashi et al., 2012). For instance, MCs and TCs are modulated differentially by the raphe nucleus (Kapoor et al., 2016) and the piriform cortex (Otazu et al., 2015). In addition, compared with MCs, TCs are less frequently inhibited by odors (Nagayama et al., 2004), respond to lower concentration odors (Igarashi et al., 2012; Kikuta et al., 2013), and have responses that are more highly correlated to olfactory sensory neuron (OSN) input (Adam et al., 2014).

Recent work has also explored differences in how the latency of odor-evoked responses differs between MCs and TCs because response latency has the potential to encode behaviorally relevant information (Cury and Uchida, 2010; Shusterman et al., 2011; Smear et al., 2011). TCs respond to odors hundreds of milliseconds earlier in the sniff cycle and show more concentrationinvariant odor-evoked response latencies than MCs (Fukunaga et al., 2012; Igarashi et al., 2012). These data suggest that MCs may use 
spike latency to encode concentration-specific information, whereas TCs may encode concentration-independent information.

In light of these emerging differences in response latency, determining the circuit-level mechanisms that drive these differences is critical. Compared with MCs, TCs are more intrinsically excitable (Burton and Urban, 2014) and receive stronger OSN input (Gire et al., 2012; Burton and Urban, 2014), suggesting that a combination of intrinsic and synaptic differences drive differential responses to changes in concentration. Little is known about whether differences in inhibition between MCs and TCs contribute to differences in odor-evoked responses. OSN stimulation evokes strong inhibition originating from both the glomerular layer and the granule cell (GC) layer onto MCs and TCs. However, the relative influence of glomerular layer circuits versus GCs in shaping odor-evoked activity in MCs and TCs remains unclear (Cleland, 2010; Fukunaga et al., 2014; Gschwend et al., 2015). Multiple GABAergic interneuron subtypes reside in the glomerular layer, including periglomerular cells (PGCs) (Kiyokage et al., 2010; Shao et al., 2012; Najac et al., 2015), superficial short-axon cells (sSACs) (Liu et al., 2013; Whitesell et al., 2013; Liu et al., 2016) and even subsets of external tufted cells (ETCs) (Tatti et al., 2014). However, whether differences in the strength of these glomerular layer circuits contribute to differences in the latency of MC and TC responses remains unknown. Computational models predict that differential input from PGCs may drive differences in spike latency between MCs and TCs (Fukunaga et al., 2012). However, other work has shown that the strengths of PGC-mediated inhibitory currents onto MCs and TC are similar when OSNs are stimulated at weak intensities (Najac et al., 2015). Therefore, a systematic investigation of how both GC- and glomerular-layer-mediated inhibitory currents onto MCs and TCs vary with stimulus intensity is needed.

Here, using whole-cell recordings in acute olfactory bulb slices, we find that MCs display longer-latency spiking that is more strongly dependent on stimulus intensity than TCs. We find that longer-latency spiking in MCs is a consequence of weaker excitatory and stronger inhibitory currents onto MCs compared with TCs. Stronger inhibitory currents onto MCs than TCs originate in the glomerular layer, so blocking glomerular layer inhibition, but not GC-mediated, inhibition led to more reliable and shorter-latency responses in MCs, but not TCs. These data suggest that differences in odor-evoked response latency between MCs and TCs are due in part to differences in glomerular-layer-mediated inhibition.

\section{Materials and Methods}

Slice preparation. Postnatal day 16-23 C57BL/6 and OMP-ChR2-YFP mice (Smear et al., 2011) mice of both sexes were anesthetized with isoflurane and decapitated. Brains were dissected into ice-cold oxygenated solution containing the following (in $\mathrm{mm}$ ): $125 \mathrm{NaCl}, 25$ glucose, $2.5 \mathrm{KCl}, 25 \mathrm{NaHCO}_{3}, 1.25 \mathrm{NaH}_{2} \mathrm{PO}_{4}, 7 \mathrm{MgCl}_{2}$, and $0.5 \mathrm{CaCl}_{2}$. Horizontal slices $(310 \mu \mathrm{m}$ thick) of the main olfactory bulb were prepared using a vibratome (VT1200S; Leica) and recovered for $15-30 \mathrm{~min}$ in $37^{\circ} \mathrm{C}$ oxygenated Ringer's solution that was identical to the dissection solution except for lower $\mathrm{Mg}^{2+}$ concentrations $\left(1 \mathrm{mM} \mathrm{MgCl}_{2}\right)$ and higher $\mathrm{Ca}^{2+}$ concentrations $\left(2 \mathrm{mM} \mathrm{CaCl}_{2}\right)$. Before recording, slices were stored in room temperature oxygenated Ringer's solution until recording.

Cell classification. As described previously (Geramita et al., 2016), TCs were identified as those cells residing completely in the superficial half of the EPL with large somas ( $>10 \mu \mathrm{m}$ in diameter). All TCs had at least one lateral dendrite and did not display the rhythmic bursting characteristic of external tufted cells (Hayar et al., 2004; Antal et al., 2006; Liu and Shipley, 2008). MCs were identified as large cells located in the MC layer (MCL). Cells with ambiguous identities- that is, those with somata that resided partially in the MCL-were excluded from analysis.
Electrophysiology. MCs/TCs were visualized using infrared differential interference contrast video microscopy. Throughout the recording process, slices were superfused continuously with $37^{\circ} \mathrm{C}$ oxygenated Ringer's solution. Current-clamp recordings were made from individual cells using electrodes filled with the following (in $\mathrm{mm}$ ): 120 potassium gluconate, $2 \mathrm{KCl}, 10 \mathrm{HEPES}, 10$ sodium phosphocreatine, $4 \mathrm{Mg}$-ATP, $0.3 \mathrm{Na}_{3} \mathrm{GTP}$, 0.2 EGTA, and 0-0.025 Alexa Fluor 594 (Life Technologies), along with $0.2 \%$ Neurobiotin (Vector Laboratories). Voltage-clamp recordings were made using electrodes filled with the following (in mM): $140 \mathrm{Cs}-$ gluconate, $10 \mathrm{HEPES}, 2 \mathrm{KCl}, 10$ sodium phosphocreatine, $3 \mathrm{Mg}$-ATP, and $0.3 \mathrm{Na}_{3} \mathrm{GTP}$, and 0.025 Alexa Fluor 594 (Life Technologies), along with $0.2 \%$ Neurobiotin (Vector Laboratories). All data were low-pass filtered at $4 \mathrm{kHz}$ and digitized at $10 \mathrm{kHz}$ using a MultiClamp $700 \mathrm{~A} \mathrm{am}-$ plifier (Molecular Devices) and an ITC-18 acquisition board (Instrutech) controlled by custom software written in Igor Pro (WaveMetrics). For electrical stimulation of OSNs, a monopolar glass electrode was filled with Ringer's solution and connected to a stimulus isolation unit (World Precision Instruments) controlled by TTL pulses from the ITC-18 acquisition board. For optogenetic stimulation, slices were illuminated $(10 \mathrm{~ms}$ light pulse) by a $470 \mathrm{~nm}$ LED (pE-100; CoolLed) directed through a $60 \times$ water-immersion objective centered on a single glomerulus with a closed field stop (Burton and Urban, 2015). All data were low-pass filtered at 4 $\mathrm{kHz}$ and digitized at $10 \mathrm{kHz}$ using a MultiClamp 700A amplifier (Molecular Devices) and an ITC-18 acquisition board (Instrutech) controlled by custom software written in Igor Pro (WaveMetrics).

Electrical and light stimulation intensities were chosen as follows. First, the minimum intensity needed to evoke reliable spiking (for current-clamp experiments) or excitatory currents (for voltage-clamp experiments) was determined. Reliability was defined as the presence of at least one spike or excitatory currents in $>80 \%$ of trials. To the find the maximum stimulation intensity, the electrical or light intensity was increased until a plateau in the number of spikes or the size of excitatory currents was reached. The middle stimulation intensity was defined as halfway between the minimum and maximum intensities. Last, the final two intensities were chosen as halfway between the minimum and middle intensities and the middle and maximum intensities. Measurements of spiking or synaptic currents were repeated seven times at each stimulation intensity. MCs and TCs were at a membrane potential between $-52 \mathrm{mV}$ and $-55 \mathrm{mV}$ throughout the current-clamp recordings.

Data analysis and statistics. For current-clamp experiments, peristimulus time histograms (PSTHs) were computed by summing spikes across trials and smoothing with a 150 -ms-wide Gaussian filter. The maximum firing rate referenced herein was calculated as the peak of the PSTH. The latency to reliable spiking was calculated in each cell by binning spikes in $10 \mathrm{~ms}$ bins and finding the percentage of trials on which the cell spiked in each time bin. "Time to reliable spiking" was defined as the first time bin after stimulation in which the cell spiked in $>80 \%$ of trials.

Significance between MCs and TCs when metrics of spike latency were plotted against PSTH peak was determined by fitting the dependence of latency on rate for each cell to an exponential function to determine $\tau$. Then, $\tau$ 's were compared between MCs and TCs using unpaired $t$ tests.

\section{Results}

To determine how MCs and TCs respond to changes in stimulus intensity, we recorded membrane potential in single MCs and TCs in olfactory bulb slices after electrical stimulation of the olfactory nerve layer adjacent to the cell's home glomerulus at multiple intensities (Fig. $1 a-c$ ). Five intensities for each cell were chosen to sample the entirety of each cell's sensory-evoked dynamic range (see Materials and Methods). Stimulation intensities in MCs ranged between $12.17 \pm 21.87 \mu \mathrm{A}$ and $180.73 \pm 95.30$ $\mu \mathrm{A}$, whereas stimulation intensities in TCs ranged between $16.80 \pm 20.8 \mu \mathrm{A}$ and $193.64 \pm 81.48 \mu \mathrm{A}$. Neither the minimum $(p=0.56$; unpaired $t$ test $)$ nor maximum $(p=0.80$; unpaired $t$ test) stimulation intensities differed between MCs and TCs. This approach allowed between-cell comparisons at each of the five intensities. 

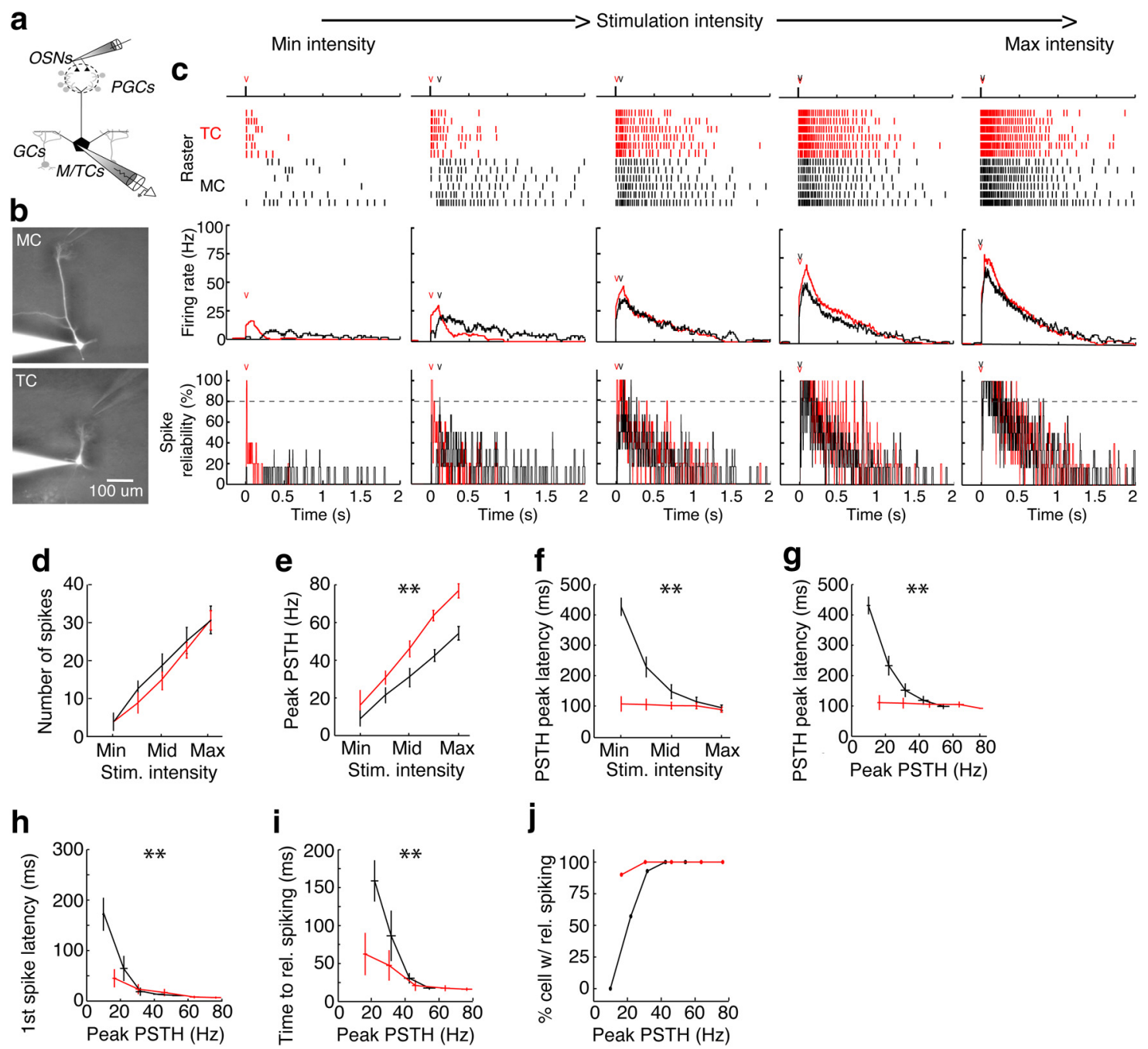

Figure 1. MCs and TCs encode the intensity of olfactory sensory neuron stimulation differently. $\boldsymbol{a}, \boldsymbol{b}$, Schematic $(\boldsymbol{a})$ and examples $(\boldsymbol{b})$ of experimental setup. Spiking responses to electrical stimulation (10 $\mu$ s) of OSNs at five intensities was recorded in either mitral ( $\boldsymbol{b}$, top) or tufted ( $\boldsymbol{b}$, bottom) cells. $\boldsymbol{c}$, Example of spike rasters (top), PSTHs (middle) and spike time reliability plots (bottom) for a MC (black) and TC (red) across 5 stimulation intensities (see Materials and Methods). Plots of spike time reliability depict the percentage of trials in which the cell fired an action potential during each $10 \mathrm{~ms}$ time bin after OSN stimulation (" $v$ " represents the first time bin after OSN stimulation during which spike timing was $>80 \%$ reliable). $\boldsymbol{d}, \mathrm{MCs}$ and TCs respond to 0SN stimulation with similar numbers of spikes $(p=0.911) . \boldsymbol{e}$, TCs, however, respond with higher firing rates, measured as the peak of the PSTH, than MCs $(p=8.8 \mathrm{e}-16) . \boldsymbol{f}-\boldsymbol{j}$, TCs respond to low-intensity OSN stimulation at shorter latencies than MCs. $\boldsymbol{f}, \boldsymbol{g}$, Latency to PSTH peak is shorter in TCs than in MCs when plotted vs stimulation intensity $(\boldsymbol{f} ; p=1.58 \mathrm{e}-9)$ or PSTH peak $(\boldsymbol{g} ; p=$ 1.15e-5). $\boldsymbol{h}, \boldsymbol{l}$, First spike latency $(\boldsymbol{h} ; \boldsymbol{p}=0.007)$ and time to first reliable spike $(\boldsymbol{i} ; p=0.0083)$ are also shorter in TCs than MCs at low stimulation intensities. $\boldsymbol{j}$, At low stimulation intensities, a larger percentage of TCs than MCs show reliable spike timing. Data were taken from $14 \mathrm{MCs}$ and $20 \mathrm{TCs}$. Significance was assessed in $\boldsymbol{d}$ - $\boldsymbol{f}$ using two-way ANOVA and in $\boldsymbol{g}$ - $\boldsymbol{i}$ as unpaired $t$ test comparing $\tau^{\prime}$ s derived from exponential fit from data in each cell. Asterisks $\left(^{* *}\right)$ in $\boldsymbol{d}-j$ indicate significant $(p<0.05)$ differences between MCs and TCs.

Given prior work showing that both spike latencies and firing rates of principal neurons vary with odor concentration (Cang and Isaacson, 2003; Fukunaga et al., 2012; Igarashi et al., 2012; Sirotin et al., 2015), we compared how spike latencies and firing rates varied with stimulation intensity in MCs and TCs. The total number of action potentials (Fig. $1 d$ ) in a $2 \mathrm{~s}$ interval after stimulation increased with intensity ( $p=1.52 \mathrm{e}-12$; 2 -way ANOVA) but did not differ between MCs and TCs. Compared with MCs, however, TCs exhibited significantly higher firing rates, as measured by the peak in the PSTH (Fig. 1e). Therefore, MCs and TCs are both capable of using firing rate to encode information about OSN stimulation intensity.

Next, we explored whether spike latency, as assessed by three different metrics, varied with OSN stimulation intensity in either MCs or TCs. First, we found that the latency to PSTH peak decreased with stimulation intensity in MCs, but not TCs (Fig. 1f). To better compare spike latency with in vivo data, we plotted the latency to PSTH peak versus peak firing rate (PSTH peak) and similarly found that the dependence of spike latency on firing rate was significantly different between MCs and TCs (Fig. 1g; see Materials and Methods). In addition, using first spike latency (Fig. $1 \mathrm{~h}$ ) and the time to reliable spiking (Fig. 1I; see Materials and Methods) as measures of latency showed that latencies in MCs vary more strongly with peak firing rate than latencies in TCs. In addition, at low firing rates $(<20 \mathrm{~Hz})$, many fewer MCs than TCs exhibited reliable spike timings (Fig. $1 j$ ), which corroborates in vivo data showing that MC response latencies are not reliable at low odor concentrations (Igarashi et al., 2012). Finally, given that MCs intrinsically exhibit upstate and downstate membrane potentials (Heyward et al., 2001), we explored whether each cell's spike latency at minimum stimulation intensities was influenced by the cell's membrane potential before OSN stimulation on a trial-by-trial basis. Spike latency, as assessed by first spike latency, did not correlate with the cell's prestimulation 
a

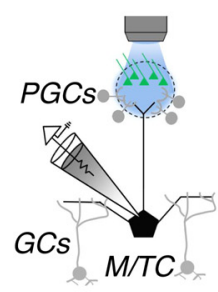

b

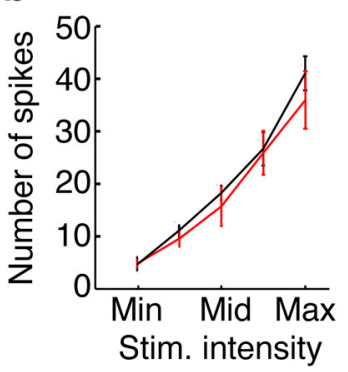

C

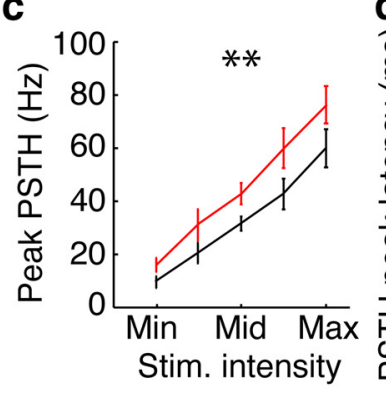

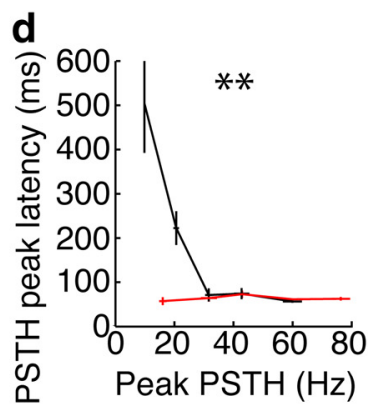

g

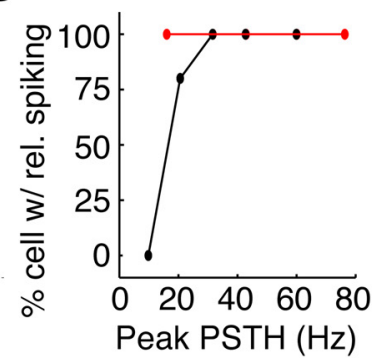

Figure 2. Optical activation of single glomeruli in olfactory bulb sections from 0MP-ChR2:EYFP mice. $\boldsymbol{a}$, Schematic of experimental setup analogous to the one used in Figure 1. Spiking in single MCs or TCs in response to photostimulation (10 ms) of a single glomerulus at five intensities. MCs and TCs respond to 0SN photostimulation with similar numbers of spikes $(\boldsymbol{b} ; p=0.4)$; however, TCs responded with higher firing rates than $\mathrm{MCs}(\boldsymbol{c} ; p=1.83 \mathrm{e}-10)$. In addition, TCs responded to low-intensity OSN photostimulation with shorter latencies than MCs as assessed by the time to $\mathrm{PSTH}$ peak $(\boldsymbol{d} ; p=0.0045)$, first spike latency $(\boldsymbol{e} ; \boldsymbol{p}=0.0023)$, and time to first reliable spike $(\boldsymbol{f} ; \boldsymbol{p}=0.004)$. $\boldsymbol{g}$, A larger percentage of TCs than MCs display reliable spike timing. Data were taken from five MCs and five TCs. Significance was assessed in $\boldsymbol{b}$ and $\boldsymbol{c}$ using two-way ANOVA and in $\boldsymbol{d}-\boldsymbol{f}$ as unpaired $t$ test comparing $\boldsymbol{\tau}^{\prime}$ s derived from exponential fit from data in each cell. Asterisks (**) in $\boldsymbol{b}-\boldsymbol{g}$ indicate significant $(p<0.05)$ differences between MCs and TCs.

membrane potential in either MCs $(r=0.07, p=0.81$, Pearson's correlation) or TCs ( $r=0.01, p=0.94$, Pearson's correlation). Therefore whereas both MCs and TCs have the potential to encode information about the intensity of glomerular activation in their firing rates, only MCs are capable of using spike latency to encode intensity information.

One potential confound to these experiments is the possibility that MC and TC apical dendrites are excited directly by electrical stimulation at strong stimulation intensities. Therefore, we performed an analogous experiment in OMP-ChR2-YFP mice (Smear et al., 2011) in which we photostimulated (10 ms pulse) the home glomerulus of the recorded cell at five light intensity chosen as described above (Fig. $2 a$ ). We found that, whereas the number of spikes increased in MCs and TCs (Fig. 2b), firing rates in TCs were significantly higher than in MCs (Fig. 2c). In addition, spike latency in MCs, but not in TCs, showed a strong dependence on firing rate. Latency to PSTH peak (Fig. $2 d$ ), first spike latency (Fig. 2e), and latency to reliable spiking (Fig. 2f) all differed significantly between MCs and TCs. In addition, fewer MCs than TCs showed reliable spike timing at low photostimulation intensities (Fig. $2 g$ ). Finally, the peak firing rates and latencies in MCs and TCs were comparable between experiments using electrical and photostimulation of OSNs. The similarity of these data with data from electrical stimulation of glomeruli indicates that direct electrical stimulation of MC or TC apical dendrites did not influence our results significantly. Therefore, our in vitro data corroborate prior in vivo findings that MCs and TCs have the potential to use distinct strategies for encoding concentration (Fukunaga et al., 2012; Igarashi et al., 2012).

To determine potential sources of these differences in how MCs and TCs respond to changes in stimulus intensity, we measured both excitatory and inhibitory currents after electrical stimulation of OSNs across five stimulation intensities (Fig.
$3 a, b)$. Previously, our group and others have shown that TCs receive stronger excitation than MCs at minimal stimulation intensities (Gire et al., 2012; Burton and Urban, 2014). However, evidence for differences in feedforward inhibition is mixed (Fukunaga et al., 2014; Najac et al., 2015). Therefore, we measured both excitatory and inhibitory currents across five stimulation intensities in MCs and TCs. We found that both the peak amplitude (Fig. $3 c$, top) and charge (Fig. $3 d$, top; calculated as the integral across $1 \mathrm{~s}$ after stimulation) of feedforward inhibition onto MCs is larger than onto TCs. However, whereas the peak amplitude of excitation was significantly larger in TCs than in MCs (Fig. $3 c$, bottom), the charge transferred did not differ between MCs and TCs (Fig. 3d, bottom). Therefore, the E/I ratio was significantly lower in MCs than in TCs (Fig. $3 f$, top). These E/I ratios, calculated across the first second after stimulation, likely allow TCs to fire at higher peak rates than MCs across all stimulation intensities. However, it cannot explain why the latency of spiking in MCs, but not TCs, is much longer at low stimulation intensities than at high stimulation intensities.

Given prior work indicating that glomerular-layer-mediated inhibition plays an important role in regulating response latency in MCs and that glomerular-layer-mediated feedforward inhibition is confined to the first $150 \mathrm{~ms}$ after OSN stimulation (Shao et al., 2012; Najac et al., 2015), we limited our analysis of excitatory and inhibitory charge transfer and E/I ratio to the first $150 \mathrm{~ms}$ after OSN stimulation. Similar to the findings described above for the $0-1000 \mathrm{~ms}$ time window, we found that inhibitory (Fig. $3 e$, top), but not excitatory (Fig. $3 e$, bottom), charge transferred during the $0-150 \mathrm{~ms}$ time window was significantly larger in MCs than TCs. In addition, the E/I ratio in this $0-150$ ms time window was significantly higher in TCs than in MCs (Fig. $3 f$, bottom). This difference in E/I ratio was largest at low stimulation intensities; the E/I ratio was $\sim 1$ in MCs and $>6$ in TCs at minimal 


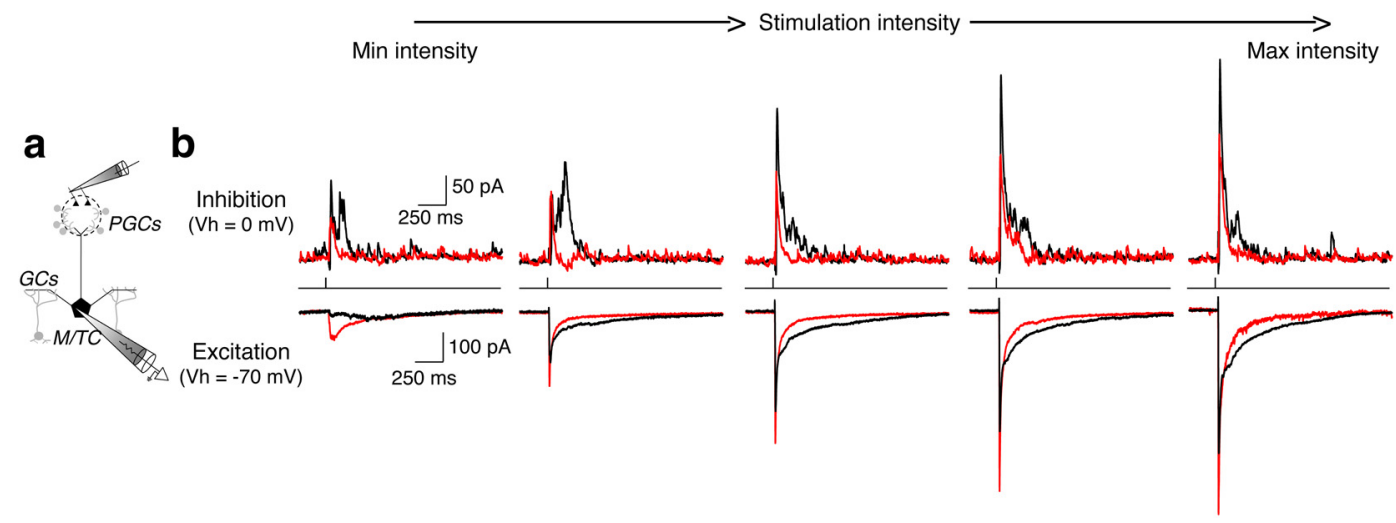

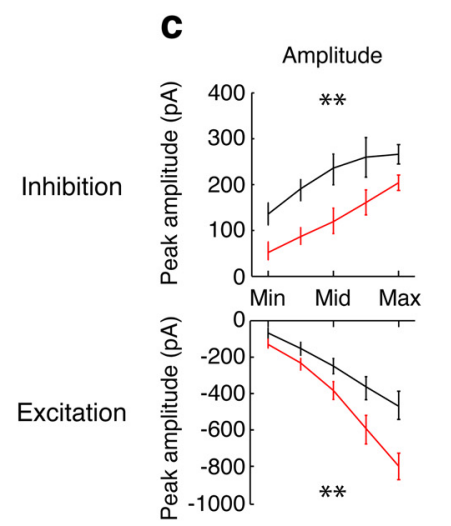
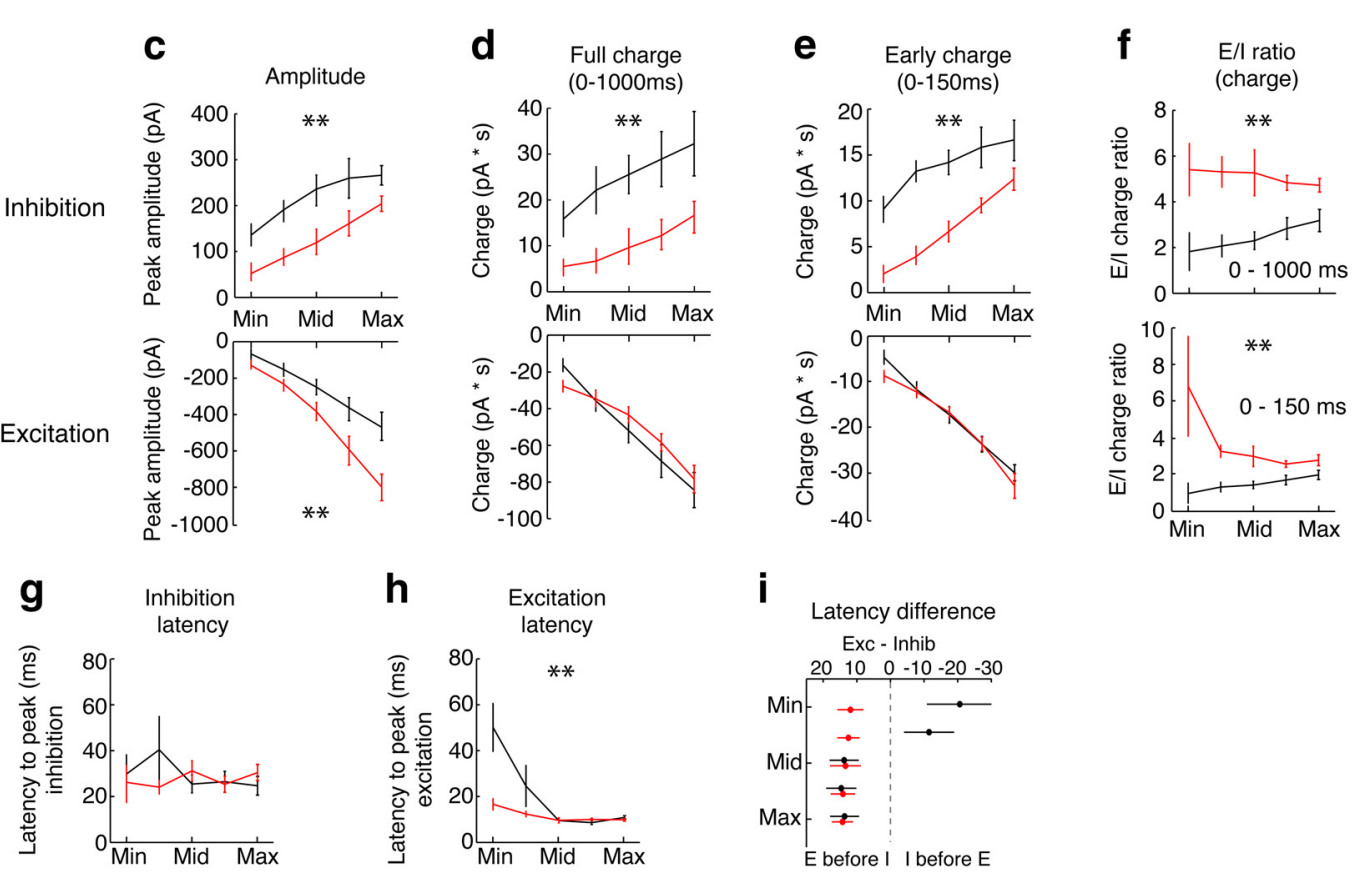
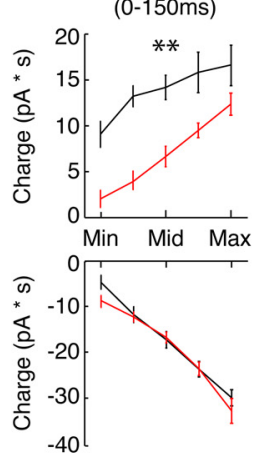

i

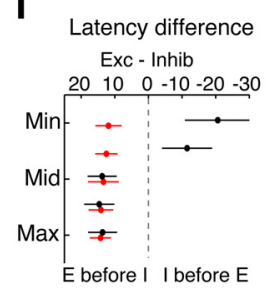

Figure 3. TCs respond to electrical stimulation of OSNs with stronger excitatory and weaker inhibitory currents than $M C s . \boldsymbol{a}, \boldsymbol{b}$, Excitatory $\left(V_{\mathrm{h}}=-70 \mathrm{mV}\right)$ and inhibitory $\left(V_{\mathrm{h}}=0 \mathrm{mV}\right)$ currents were measured in single MCs or TCs after electrical stimulation of OSNs at five intensities. $\boldsymbol{b}$, Examples of inhibitory (top) and excitatory (bottom) currents at each of the five stimulation intensities in one example MC (black) and TC (red). $\mathbf{c}-\boldsymbol{e}$, Comparisons of inhibitory (top) and excitatory current peak amplitude (c), charge in $1 \mathrm{~s}$ after stimulation (d), and charge in first $150 \mathrm{~ms}$ after stimulation (e) between MCs and TCs. Compared with TCs, inhibitory currents in MCs have larger peak amplitudes ( $p=5.36 \mathrm{e}-18)$ and charge transferred in the $1 \mathrm{~s}$ after stimulation $(p=3.16 \mathrm{e}-8)$ and the first $150 \mathrm{~ms}$ after stimulation $(p=7.56 \mathrm{e}-10)$. However, excitatory currents in MCs have larger peak currents $(p=4.58 \mathrm{e}-14)$, but similar charge transferred in the $1 \mathrm{~s}$ after stimulation $(p=0.47)$ and the first $150 \mathrm{~ms}$ after stimulation $(p=0.18$ ) compared with TCs. $f$, Ratio of excitatory to inhibitory currents is larger in TCs than in MCs when calculated as the ratio of charge transferred during $1 \mathrm{~s}$ after stimulation (top; $p=4.2 \mathrm{e}-7$ ) or during the first $150 \mathrm{~ms}$ after stimulation (bottom; $p=0.0005$ ). $\boldsymbol{g}, \boldsymbol{h}$, Latency to the peak of inhibitory currents does not differ between MCs and TCs ( $\boldsymbol{g} ; p=$ $0.40)$; however, the latency to the peak of excitatory currents differs between MCs and TCs ( $\boldsymbol{h} ; \boldsymbol{p}=0.001) . \boldsymbol{i}$, At all five intensities, the peak of excitatory currents precedes inhibition in TCs. However, in MCs, excitation lags inhibition at the weakest two intensities, but leads inhibition at the strongest three intensities. Data were taken from eight MCs and eight TCs and are plotted as mean \pm SEM. Significance was assessed using two-way ANOVA. Asterisks $\left(^{* *}\right)$ in $c-i$ indicate significant $(p<0.05)$ differences between MCs and TCs.

stimulation intensities. Therefore, longer-latency spiking in MCs than in TCs at these low intensities is predominantly driven by large inhibitory currents during the first $150 \mathrm{~ms}$ after stimulation. Finally, we analyzed how the latency to the peak amplitudes of inhibition and excitation change across stimulation intensities. Although the latency to the peak of inhibition did not vary with stimulation intensity ( $p=0.60 ; 2$-way ANOVA) or between MCs and TCs (Fig. 3g), the latency to the peak of excitation did vary with stimulation intensity ( $p=1.10 \mathrm{e}-5 ; 2$-way ANOVA) and between MCs and TCs (Fig. 3h). Interestingly, in TCs, the peak of excitation preceded the peak of inhibition at all intensities. However, in MCs, excitation led inhibition at high stimulation intensities but lagged inhibition at low intensities (Fig. 3i). This shift from excitation lagging inhibition to excitation leading inhibition likely reflects prior work showing that, at weak stimulation intensities, MCs primarily receive indirect excitation from ETCs (Gire et al., 2012) and, at higher intensities, MCs receive both indirect and direct excitation from OSNs (De Saint Jan and Westbrook, 2007; De Saint Jan et al., 2009; Najac et al., 2011; Vaaga and Westbrook, 2016).

To test directly whether larger inhibitory currents onto MCs and TCs are mediated by glomerular layer circuits, we measured glomerular-layer-mediated inhibitory currents by photostimulating the home glomerulus of the recorded MC/TC in OMPChR2 mice while limiting GC-mediated inhibition by blocking mGluR1s (LY36785, $100 \mu \mathrm{M}$ ) and NMDARs (AP-5, $25 \mu \mathrm{M}$ ) as described previously (Fig. 4a,b; Najac et al., 2015; Geramita et al., 2016). Because the differences in spike timing are greatest at minimal stimulation intensities, we compared glomerular-layermediated currents between MCs and TCs at the minimum intensity 

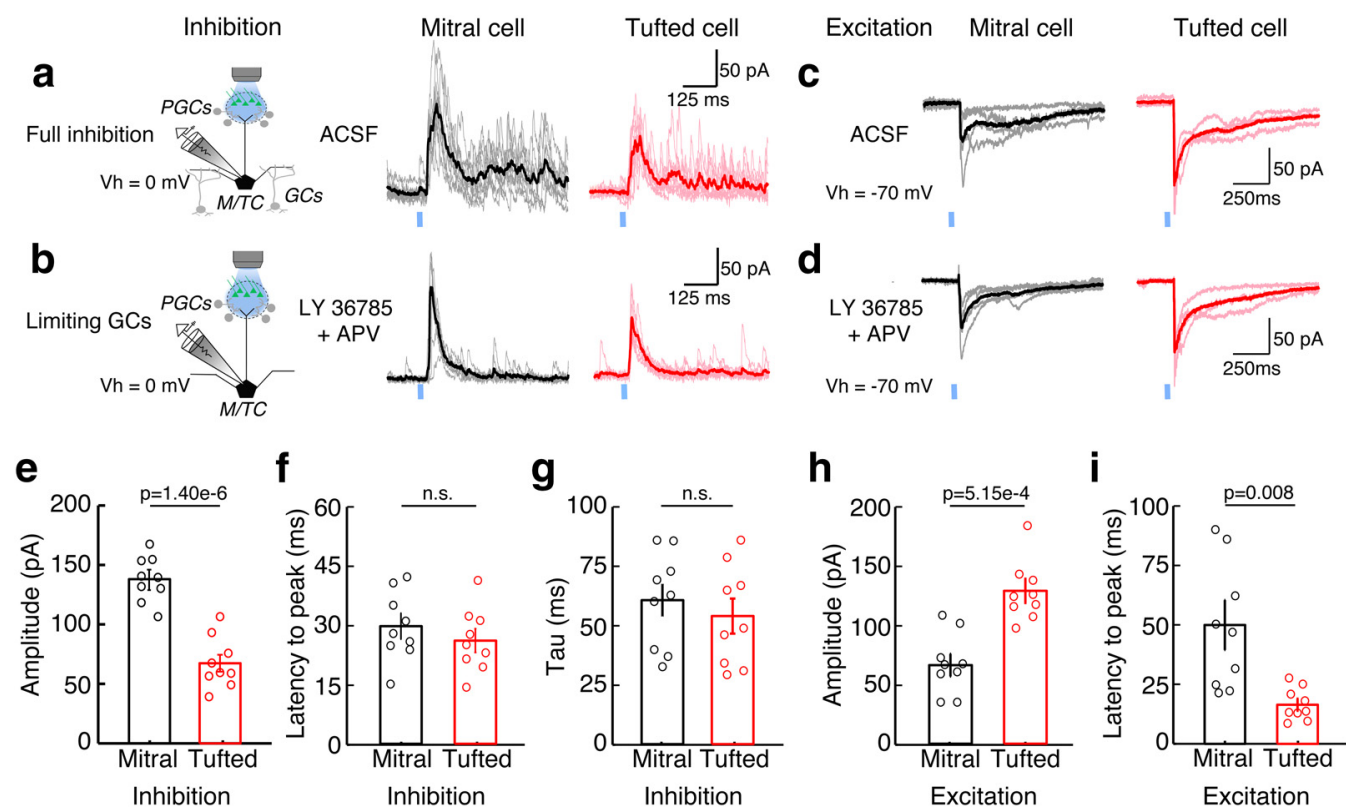

Figure 4. MCs receive stronger PGC-mediated inhibition than TCs. Inhibitory $(\boldsymbol{a}, \boldsymbol{b})$ and excitatory $(\boldsymbol{c}, \boldsymbol{d})$ currents in MCs and TCs were measured before and after limiting GC-mediated inhibition by blocking mGluRs (LY36785, $100 \mu \mathrm{M}$ ) and NMDARs (APV, $25 \mu \mathrm{M})$. Currents were evoked using photostimulation in OMP-ChR2-YFP mice at minimal stimulation intensities. $\boldsymbol{e}$, Peak amplitude of PGC-mediated inhibition is larger in MCs than in TCs $(p=1.40 \mathrm{e}-6) . \boldsymbol{f}, \boldsymbol{g}$, Latency to peak of inhibition $(\boldsymbol{f} ; p=0.56)$ and the duration of inhibition $(\boldsymbol{g} ; p=0.89$; comparing exponential decay constants of currents) did not differ between MCs and TCs. $\boldsymbol{h}$, Peak amplitude of excitatory currents was larger in TCs than in MCs ( $p=5.15 \mathrm{e}-4) . \boldsymbol{i}$, Latency to the peak of excitatory currents is longer in MCs than in TCs $(p=0.006)$. Data were taken from nine MCs and nine TCs and are plotted as mean \pm SEM. Significance was assessed using paired $t$ tests.

needed to elicit reliable excitatory currents. Glomerular-layer-mediated inhibitory currents were larger in amplitude in MCs than in TCs (Fig. 4e). There were no differences between MCs and TCs in the latency to the peak of inhibition (Fig. $4 f$ ) or the duration of inhibition (Fig. 4g; see Materials and Methods). In addition, we measured excitatory currents and found that blockade of NMDARs and mGluRs did not affect the amplitude or duration of excitatory currents in either MCs or TCs (Fig. $4 c, d$ ). Similar to the results from electrical stimulation experiments, excitatory currents were larger (Fig. 4h) and peaked at shorter latencies (Fig. $4 i)$ in TCs than in MCs. Therefore, at minimal stimulation intensities, MCs receive weaker and longer latency excitatory inputs and stronger glomerular-layer-mediated inhibitory currents compared with TCs.

Next, we tested how blocking specific inhibitory interneuron subtypes affected spiking in MCs and TCs. First, we measured spiking elicited by electrically stimulating OSNs at three different intensities (minimum, maximum, and middle) before and after limited GC-mediated inhibition by blocking NMDARs and mGluRs (Fig. $5 a, b)$. Limiting GC-mediated inhibition did not significantly affect the number of spikes (Fig. $5 c$ ), the maximum firing rate (Fig. $5 d$ ), or the latency of spiking as measured by either latency to PSTH peak (Fig. 5e) or the latency to reliable spiking (Fig. $5 f$ ) in either MCs or TCs at any of the three stimulation intensities. Although we cannot rule out the possibility that GCs contribute to M/TC spike timing and synchrony, our results suggest that GCs do not strongly influence peak firing rates or spike latencies after OSN stimulation.

To test whether blocking glomerular-layer-mediated inhibition affects spiking in MCs and TCs differentially, we measured spiking elicited by electrically stimulating OSNs at three different intensities before and after puffing gabazine into the recorded cell's home glomerulus (Fig. $6 a-d$ ). In MCs, after blocking glomerular-layer-mediated inhibition, the total number of spikes (Fig. 6e) elicited increased at all three stimulation intensities.
However, in TCs, the number of spikes increased only at the lowest stimulation intensity. In addition, the maximal firing rate increased at all three stimulation intensities (Fig. $6 f$ ) in both MCs and TCs. Increases in firing rate despite the lack of changes in the total number of spikes in TCs at the middle and maximum intensities in TCs implies that the timing of spikes is redistributed after reducing glomerular-layer-mediated inhibition. Although glomerular-layer-mediated inhibition increased peak firing rates by similar amounts in MCs and TCs at the lowest stimulation intensity (Fig. $6 \mathrm{~g}$, left), increases in peak firing rates were significantly larger in MCs than in TCs at the stronger two stimulation intensities (Fig. $6 g$, middle, right).

Glomerular-layer-mediated inhibition also affected spike latency more strongly in MCs than in TCs. At the weakest two stimulation intensities, the latency to PSTH peak became significantly shorter in MCs, but not in TCs, after blocking glomerularlayer-mediated inhibition (Fig. 6h). In addition, spike timing in MCs became more reliable at the weakest stimulation intensity after blocking glomerular-layer-mediated inhibition. Before blocking glomerular-layer-mediated inhibition, none of the four MCs showed reliable spike timing; however, after puffing gabazine in the glomerulus, spike timing in all four MCs became reliable and the latency to reliable spiking became comparable to TCs (Fig. 6i, left). In addition, the latency to reliable timing became shorter in MCs at the middle intensity after blocking glomerular-layer-mediated inhibition, but did not change in TCs at any of the three stimulation intensities (Fig. 6i). Finally, significant tonic inhibition exists within the glomerular circuit (Aroniadou-Anderjaska et al., 2000; Shao et al., 2009) and could contribute to differences in stimulus-evoked responses. Therefore, we compared spontaneous activity in MCs and TCs before and after puffing gabazine into the glomerulus (Fig. 6j). Spontaneous spiking was low in both MCs and TCs before gabazine application (MCs: $0.28 \pm 0.21 \mathrm{~Hz}$; TCs: $0.26 \pm 0.18 ; p=0.87$ unpaired $t$ test) and increased significantly in both MCs and TCs 
by similar amounts after gabazine application (MCs: $1.12 \pm 0.75 \mathrm{~Hz}$; TCs: $1.05 \pm$ $0.73 ; p=0.90$ unpaired $t$ test). Therefore, whereas tonic inhibition is present in both MCs and TCs, it cannot explain the differences in reliability and spike latency between MCs and TCs. Therefore glomerularlayer-mediated inhibition regulates the reliability and latency of spike timing more strongly in MCs than in TCs.

\section{Discussion}

Here, we show that MCs, but not TCs, show long latency responses at weak stimulation intensities that shorten with increasing intensity, largely mirroring what has been observed in vivo with increasing odor concentration (Fukunaga et al., 2012; Igarashi et al., 2012). We found that these differences are likely due to stronger inhibitory currents and weaker excitatory currents onto MCs than onto TCs. Differences in inhibition are largest during the first $150 \mathrm{~ms}$ after stimulation and are mediated predominately by glomerular layer circuits. In addition, we show that, after blocking glomerular-layermediated, but not GC-mediated, inhibition, the latency of responses in MCs becomes shorter and more reliable.

These data support an emerging view that MCs and TCs are influenced differentially by glomerular layer sources of inhibition, which cause differences in spike latency between MCs and TCs (Fukunaga et al., 2012; Fukunaga et al., 2014). We corroborate prior work and show that, at weak stimulation intensities, MCs primarily receive indirect excitatory input from ETCs that peaks $\sim 50 \mathrm{~ms}$ after stimulation (De Saint Jan and Westbrook, 2007; De Saint Jan et al., 2009; Gire and Schoppa, 2009; Najac et al., 2011; Smear et al., 2011; Gire et al., 2012; Najac et al., 2015; Vaaga and Westbrook, 2016). As the stimulation intensity increases, direct connections from OSNs onto MCs are recruited and the latency to the peak of excitation shortens. Conversely, TCs receive strong and direct excitation from OSNs at all stimulation intensities, so the peak of excitation does not vary with stimulation intensity. In both MCs and TCs, inhibitory currents peak $\sim 30 \mathrm{~ms}$ after stimulation. Therefore, in TCs, the peak of excitation precedes inhibition regardless of stimulation intensity. In MCs, however, the peak of excitation lags inhibition at weak stimulation intensities, but leads to inhibition at higher stimulation intensities. Stronger glomerular-layer-mediated inhibitory currents onto MCs than TCs work cooperatively with these differences in the source and relative strength of excitation to cause the latency of MC spiking to vary with stimulation intensity.
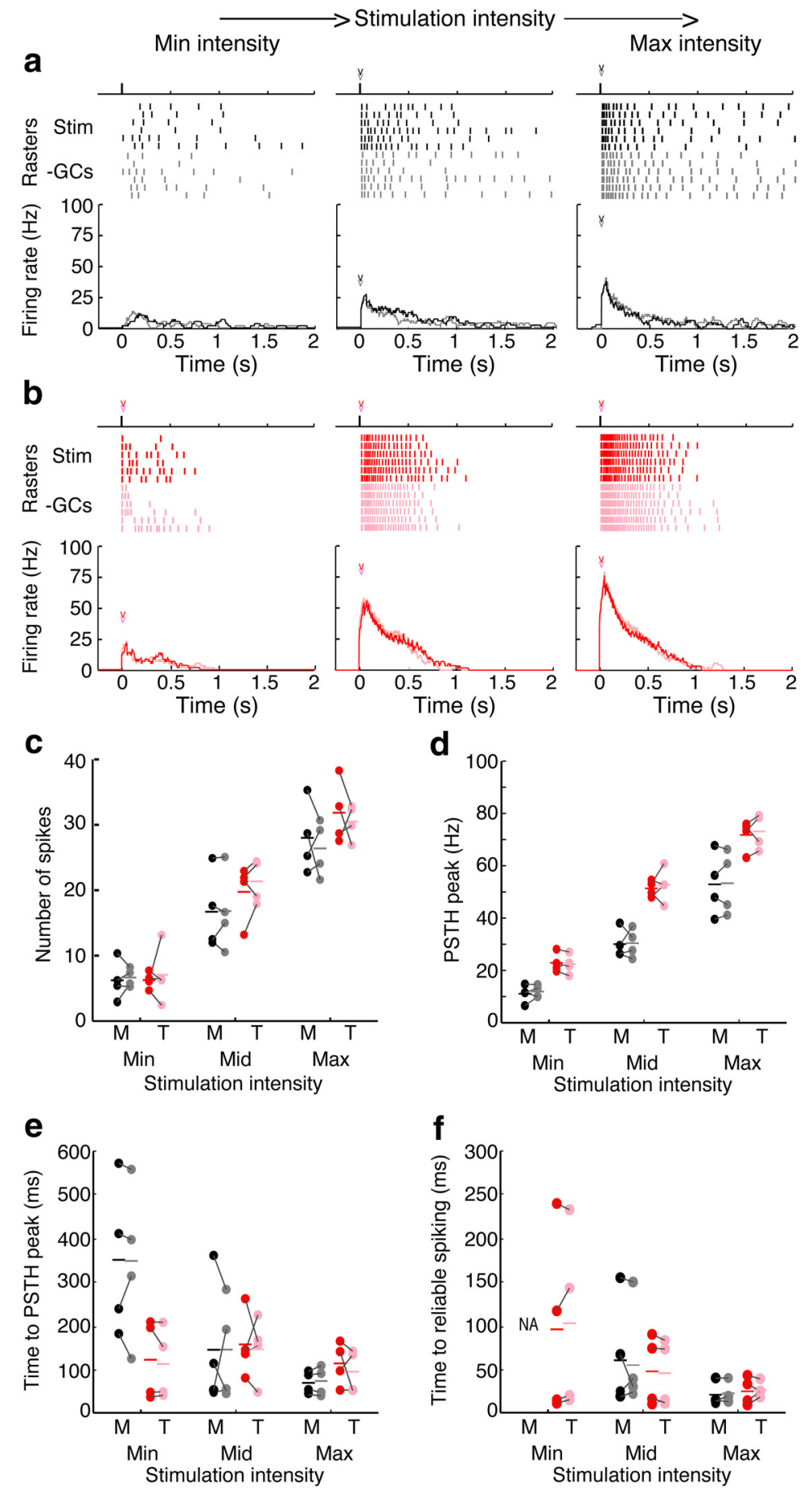

Figure 5. Blocking GC-mediated inhibition does not alter firing rates or spike latencies in MCs or TCs. $\boldsymbol{a}, \boldsymbol{b}$, Example spike rasters after electrical stimulation of OSNs at three intensities in a MC $(\boldsymbol{a})$ and a TC (b) before (black/red) and after (gray/pink) limiting GC-mediated inhibition by blocking mGluRs (LY36785) and NMDARs (APV). c, GC-mediated inhibition does not affect the number of spikes in either MCs (minimum, $p=0.72$; Mid $-p=0.97$; maximum, $p=0.57$ ) or TCs (minimum, $p=0.73 ;$ middle, $p=0.29$; maximum, $p=0.64$ ). $\boldsymbol{d}$, GC-mediated inhibition does not affect peak firing rates (PSTH peak) in either MCs (minimum, $p=0.49$; middle, $p=0.91$; maximum, $p=0.81$ ) or TCs (minimum, $p=0.56$; middle, $p=0.67$; maximum, $p=0.62) . e, f$, GC-mediated inhibition does not affect response latency as measured by the time to PSTH peak (e) in either MCs (minimum, $p=0.93$; middle, $p=0.97$; maximum, $p=0.58$ ) or TCs (minimum, $p=0.44$; middle, $p=0.79$; maximum, $p=0.53$ ) or the time to reliable spiking $(\boldsymbol{f})$ in either MCs (minimum, NA; middle, $p=0.67$; maximum, $p=0.29$ ) or TCs (minimum, $p=0.38 ;$ middle, $p=0.50$; maximum, $p=0.73$ ). Data were taken from four MCs and four TCs. Significance was assessed using paired $t$ tests.

Which glomerular layer inhibitory interneuron subtypes inhibit MCs preferentially over TCs? Prior in vivo work suggests that PGCs are responsible for differences in spike latency between MCs and TCs (Fukunaga et al., 2012; Fukunaga et al., 2014). 

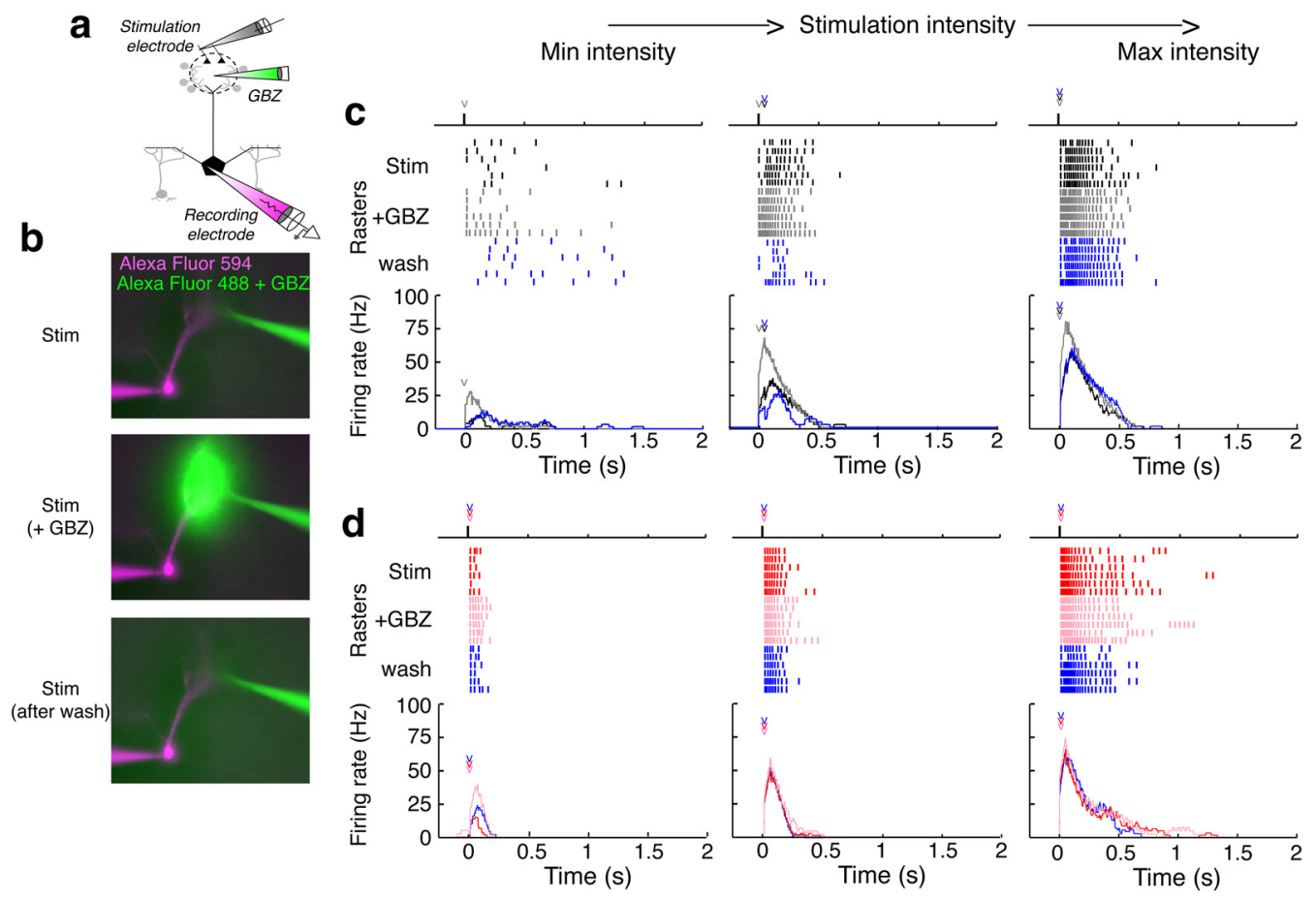

e

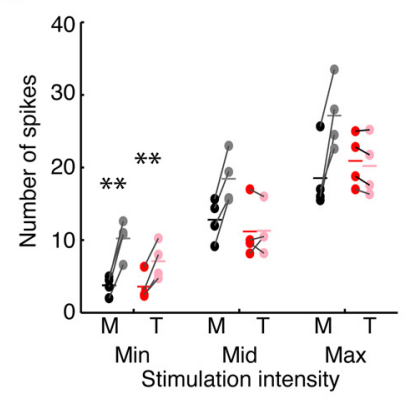

h

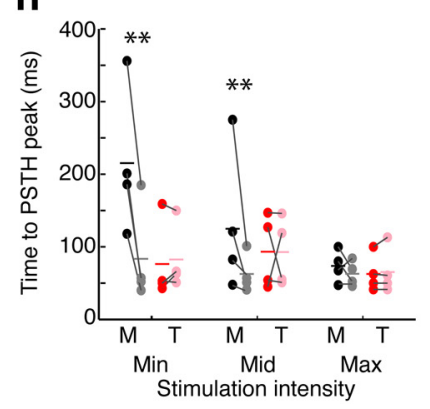

f

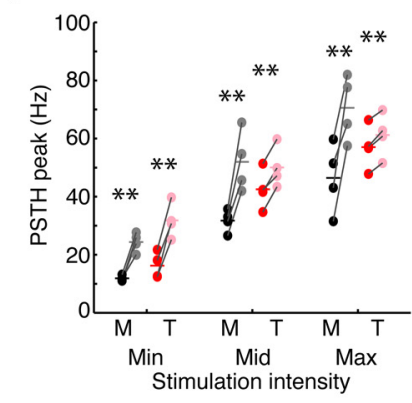

i

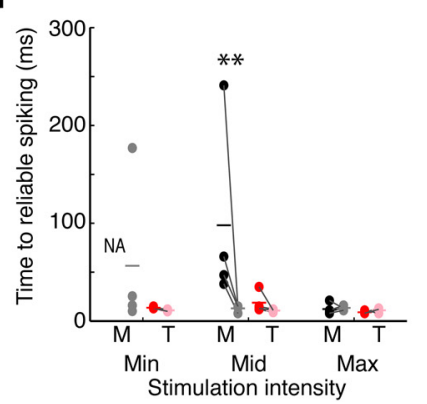

g

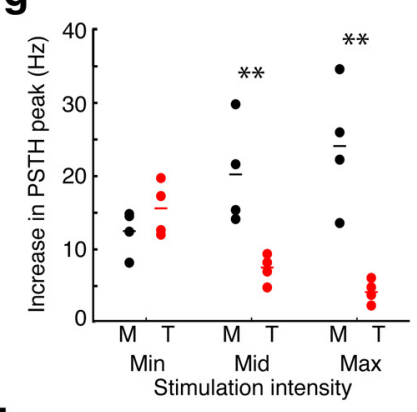

j

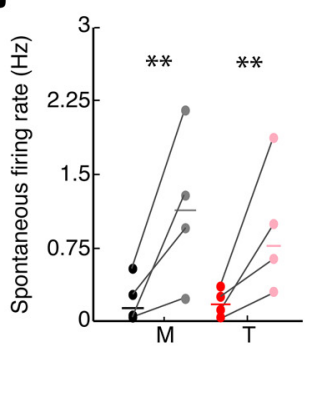

Figure 6. Blocking glomerular-layer-mediated inhibition alters firing rates and spike latencies in MCs and TCs. $\boldsymbol{a}, \boldsymbol{b}$, Spikes were measured before and after puffing gabazine in the recorded cell's home glomerulus to limit glomerular-layer-mediated inhibition. $\boldsymbol{c}, \boldsymbol{d}$, Spike rasters in a MC (c) and TC (d) before (black/red), during (gray/pink), and after (blue) blocking glomerular-layer-mediated inhibition. $\boldsymbol{e}$, Blocking glomerular-layer-mediated inhibition increased the number of spikes in MCs at all three stimulation intensities (minimum, $p=0.003$; middle, $p=0.005 ;$ maximum, $p=$ 0.0075 ) and in TCs at the weakest intensity (minimum, $p=0.0078$; middle, $p=0.91$; maximum, $p=0.12$ ). $\boldsymbol{f}$, Blocking glomerular-layer-mediated inhibition increased the firing rate, as measured by the peak of the PSTH, at all three intensities in both MCs (minimum, $p=0.0039 ;$ middle, $p=0.011$; maximum, $p=0.012$ ) and TCs (minimum, $p=0.0027 ;$ middle, $p=0.037 ;$ maximum, $p=$ 0.0023 ). $\boldsymbol{g}$, Firing rates, however, were more strongly affected by blocking glomerular-layer-mediated inhibition in MCs than in TCs at the strongest two intensities (minimum, $p=0.22$; middle, $p=0.014$; maximum, $p=0.0039$ ). $\boldsymbol{h}$, Blocking glomerular-layer-mediated inhibition reduced the latency to the PSTH peak in MCs at the weakest two intensities (minimum, $p=0.007$; middle, $p=0.018$; maximum, $p=0.56$ ), but did not affect the latency in TCs (minimum, $p=0.43$; middle, $p=0.98$; maximum, $p=0.48$ ). $\boldsymbol{i}$, Latency to reliable spiking did not change in TCs after glomerular-layer-mediated inhibition blockade (minimum, $p=0.09$; middle, $p=0.13$; maximum, $p=0.57$ ); however, in MCs, the timing of responses in all four MCs became reliable at the weakest intensity and latency was reduced at the middle $(p=0.03)$, but not the maximum $(p=0.75)$, intensity. $\boldsymbol{j}$, Spontaneous firing rates of both $\operatorname{MCs}(p=0.0034)$ and TCs $(p=0.0054)$ increased after puffing gabazine. Data were taken from four MCs and four TCs. Significance was assessed using paired $t$ tests. Asterisks $(* *)$ in $\boldsymbol{e}-i$ indicate significant $(p<0.05)$ differences between MCs and TCs. 
Stronger PGC-mediated inhibition onto MCs than TCs may be explained by multiple mechanisms. PGC synapses onto MCs may be stronger or more numerous than synapses onto TCs. Alternatively, separate populations of PGCs may target MCs and TCs preferentially. Subsets of PGCs have been identified both functionally and molecularly. Functionally, PGCs are classified by whether they receive excitation from OSNs or ETCs (Hayar et al., 2004; Shao et al., 2009). In addition, PGCs are molecularly heterogeneous (Kosaka et al., 1998; Parrish-Aungst et al., 2007; Kiyokage et al., 2010). Alternatively, differences in sSAC-mediated (Shao et al., 2013; Whitesell et al., 2013; Liu et al., 2016) or ETCmediated (Tatti et al., 2014) inhibition may contribute to differences in glomerular-layer-mediated inhibition onto MCs and TCs. Expressing channelrhodopsin in specific cell types (Fukunaga et al., 2014; Banerjee et al., 2015; Liu et al., 2016) will be vital for determining whether and the extent to which each cell type contributes to differences in inhibition between MCs and TCs.

Whether animals use spike latency of MCs and/or TCs to determine odor concentration is an unanswered question that will play an important role in interpreting these data. Although prior work has shown that animals can be trained to use latency to encode behaviorally relevant information (Smear et al., 2011), whether animals normally use latency to encode concentrationspecific information is unknown. If MCs do encode concentration with spike latency, then the concentration invariance of TC latency (Fukunaga et al., 2012; Igarashi et al., 2012) suggests that TCs may play an important role in identifying odors across a wide range of odor concentrations. However, if animals do not use latency to determine odor concentration and instead use firing rates exclusively, then an alternative purpose for longer-latency spiking in MCs is needed. For instance, odor identity may be encoded by MC spike latency (Hopfield, 1995; Brody and Hopfield, 2003). Therefore, whereas the absolute latency of MC spiking may vary with concentration, the relative differences in MC latency across the population remains constant so that the representation of odor identity remains concentration invariant (Schaefer and Margrie, 2007; Uchida et al., 2014). Alternatively, MCs and TCs may be responsible for encoding olfactory information in separate concentration ranges and only cells spiking early in the sniff cycle may encode task-specific information (Geramita et al., 2016). This view implies that intrinsic and circuit-level factors that cause longer-latency spiking in MC serves to reduce redundant spikes early in the sniff cycle. Data showing that spike latency in MCs is unreliable at low stimulus intensities (Igarashi et al., 2012) and the fact that TCs have lower odor thresholds (Nagayama et al., 2004; Kikuta et al., 2013) implies that, at least at low odor concentrations, odor identity information is primarily encoded by TCs. Finally, other aspects of olfactory bulb circuitry support concentration-specific ranges for MCs and TCs. For instance, differences in the sources and effects of lateral inhibition onto MCs and TCs allow each to best perform odor discriminations in separate concentrations ranges (Geramita et al., 2016). Future experiments exploring how odor identification or discrimination at low concentrations is affected by either chemical or optical silencing of TCs will be needed to determine the extent to which MCs and TCs contribute to encoding olfactory information at low versus high odor concentrations.

We note, however, that our in vitro approach has certain limitations. In particular, increasing the intensity of electrical stimulation of OSNs that project to a single glomerulus does not reflect all of the changes that occur as the concentration of an odor increases. For instance, as odor concentration increases, not only does the strength of glomerular activation increase, but also more glomeruli are recruited. Therefore, the experiments presented here cannot determine the extent to which spike timing in MCs and TCs is influenced by changes in lateral inhibition that occur when more glomeruli are recruited. However, recent work has begun to explore how differences in lateral inhibition between MCs and TCs influence odor coding at distinct concentration ranges (Geramita et al., 2016). In addition, electrical stimulation may introduce artifacts that could confound our conclusions. For instance, increasing stimulation intensity broadens the current spread around the electrode and potentially recruits more OSNs. Therefore, if TCs have larger apical dendritic arbors than MCs, then TCs would be more likely to be activated at lower stimulation intensities than MCs. However, experiments performed in OMPChR2 mice in which glomeruli were optically stimulated yielded results that are comparable to experiments in which glomeruli were stimulated electrically. Therefore, the differences in spike timing and reliability between MCs and TCs are unlikely to be completely explained by artifacts of the electrical stimulation paradigm.

What are other consequences of stronger glomerular-layermediated inhibition onto MCs? Blocking glomerular-layermediated inhibition affects the magnitude and latency of firing rates more strongly in MCs than in TCs, indicating that glomerular layer circuits may play a critical role in the higher firing rates observed in TCs in vitro and in vivo (Nagayama et al., 2004; Igarashi et al., 2012). Although weaker input from glomerular layer circuits and stronger excitation allows a larger dynamic range of excitatory responses in TCs than in MCs, glomerular-layermediated inhibition may also be responsible for the more robust inhibitory responses observed in vivo in MCs (Nagayama et al., 2004). Indeed, both computational and in vivo work suggests that feedforward inhibition mediated by PGCs is the most likely explanation for odor-evoked inhibition commonly observed in MCs (Cleland, 2010; Fukunaga et al., 2012; Fukunaga et al., 2014). Functionally, these differences in glomerular-layer-mediated inhibition onto MCs and TCs may play an important role in decorrelating firing rates between MCs and TCs that project to the same glomerulus (i.e., homotypic MCs/TCs). Future in vivo experiments that monitor odor-evoked responses in homotypic MCs and TCs will be vital for determining how TCs respond to odors that inhibit MCs. In addition to driving decorrelation of homotypic $\mathrm{MC}$ and $\mathrm{TC}$ firing rates, it is temping to speculate that differences in PGC-mediated inhibition between homotypic MCs may be one mechanism, in addition to other known intrinsic differences (Padmanabhan and Urban, 2010), responsible for heterogeneous odor responses between homotypic MCs (Dhawale et al., 2010). Supporting this idea, blocking glomerularlayer-mediated inhibition in vitro reduces spike time variability in MCs (Najac et al., 2015). Future studies measuring odorevoked responses in homotypic MCs before and after blocking inhibition from various interneuron subtypes may help to resolve the circuit-level mechanisms behind unique temporal dynamics in individual MCs.

Segregating sensory information presented in specific intensity ranges in parallel neuron types is a common strategy in sensory systems. The data presented here and elsewhere strongly indicate that MCs and TCs are responsible for encoding odor information presented at high and low concentrations, respectively. Similarly, distinct touch receptors in the skin respond to tactile stimulation in separate pressure ranges. In addition, rods and cones encode visual information in largely separate intensity ranges. Given these similarities, it is temping to draw further analogies between sensory systems. For instance, in the visual 
system, three separate light intensity ranges have been described based on the type of photoreceptors that mediate vision in each range. In low-intensity light conditions, scotopic vision is mediated by rods, whereas in high-intensity light conditions, photopic vision is mediated by cones. Mesopic vision is thus defined as the intermediate range of light intensities in which visual information is encoded by both rods and cones. Because both rods and cones relay information through separate neural pathways in the retina and have distinct temporal responses, modeling how these signals are combined at these intermediate-intensity light levels becomes quite challenging (Stockman and Sharpe, 2006). Moving forward, determining whether three analogous ranges of odor concentration can be defined based on the responses of MCs and TCs will be vital. Given the added complexities of understanding olfactory coding in concentration regimes when both MCs and TCs are activated, it will be important to determine how each population encodes odors in isolation by studying responses in concentration ranges that only engage MCs or TCs.

\section{References}

Adam Y, Livneh Y, Miyamichi K, Groysman M, Luo L, Mizrahi A (2014) Functional transformations of odor inputs in the mouse olfactory bulb. Front Neural Circuits 8:129. CrossRef Medline

Antal M, Eyre M, Finklea B, Nusser Z (2006) External tufted cells in the main olfactory bulb form two distinct subpopulations. Eur J Neurosci 24:1124-1136. CrossRef Medline

Aroniadou-Anderjaska V, Zhou FM, Priest CA, Ennis M, Shipley MT (2000) Tonic and synaptically evoked presynaptic inhibition of sensory input to the rat olfactory bulb via GABA(B) heteroreceptors. J Neurophysiol 84: 1194-1203. Medline

Banerjee A, Marbach F, Anselmi F, Koh MS, Davis MB, Garcia da Silva P, Delevich K, Oyibo HK, Gupta P, Li B, Albeanu DF (2015) An interglomerular circuit gates glomerular output and implements gain control in the mouse olfactory bulb. Neuron 87:193-207. CrossRef Medline

Brody CD, Hopfield JJ (2003) Simple networks for spike-timing-based computation, with application to olfactory processing. Neuron 37:843852. CrossRef Medline

Burton SD, Urban NN (2014) Greater excitability and firing irregularity of tufted cells underlies distinct afferent-evoked activity of olfactory bulb mitral and tufted cells. J Physiol 592:2097-2118. CrossRef Medline

Burton SD, Urban NN (2015) Rapid feedforward inhibition and asynchronous excitation regulate granule cell activity in the mammalian main olfactory bulb. J Neurosci 35:14103-14122. CrossRef Medline

Cang J, Isaacson JS (2003) In vivo whole-cell recording of odor-evoked synaptic transmission in the rat olfactory bulb. J Neurosci 23:4108-4116. Medline

Cleland TA (2010) Early transformations in odor representation. Trends Neurosci 33:130-139. CrossRef Medline

Cury KM, Uchida N (2010) Robust odor coding via inhalation-coupled transient activity in the mammalian olfactory bulb. Neuron 68:570-585. CrossRef Medline

De Saint Jan D, Westbrook GL (2007) Disynaptic amplification of metabotropic glutamate receptor 1 responses in the olfactory bulb. J Neurosci 27:132-140. CrossRef Medline

De Saint Jan D, Hirnet D, Westbrook GL, Charpak S (2009) External tufted cells drive the output of olfactory bulb glomeruli. J Neurosci 29:20432052. CrossRef Medline

Dhawale AK, Hagiwara A, Bhalla US, Murthy VN, Albeanu DF (2010) Nonredundant odor coding by sister mitral cells revealed by light addressable glomeruli in the mouse. Nat Neurosci 13:1404-1412. CrossRef Medline

Fukunaga I, Berning M, Kollo M, Schmaltz A, Schaefer AT (2012) Two distinct channels of olfactory bulb output. Neuron 75:320-329. CrossRef Medline

Fukunaga I, Herb JT, Kollo M, Boyden ES, Schaefer AT (2014) Independent control of gamma and theta activity by distinct interneuron networks in the olfactory bulb. Nat Neurosci 17:1208-1216. CrossRef Medline

Geramita MA, Burton SD, Urban NN (2016) Distinct lateral inhibitory circuits drive parallel processing of sensory information in the mammalian olfactory bulb. eLife 5: pii: e16039. CrossRef Medline
Gire DH, Schoppa NE (2009) Control of on/off glomerular signaling by a local GABAergic microcircuit in the olfactory bulb. J Neurosci 29:1345413464. CrossRef Medline

Gire DH, Franks KM, Zak JD, Tanaka KF, Whitesell JD, Mulligan AA, Hen R, Schoppa NE (2012) Mitral cells in the olfactory bulb are mainly excited through a multistep signaling path. J Neurosci 32:2964-2975. CrossRef Medline

Gschwend O, Abraham NM, Lagier S, Begnaud F, Rodriguez I, Carleton A (2015) Neuronal pattern separation in the olfactory bulb improves odor discrimination learning. Nat Neurosci 18:1474-1482. CrossRef Medline

Hayar A, Karnup S, Ennis M, Shipley MT (2004) External tufted cells: a major excitatory element that coordinates glomerular activity. J Neurosci 24:6676-6685. CrossRef Medline

Heyward P, Ennis M, Keller A, Shipley MT (2001) Membrane bistability in olfactory bulb mitral cells. J Neurosci 21:5311-5320. Medline

Hopfield JJ (1995) Pattern recognition computation using action potential timing for stimulus representation. Nature 376:33-36. CrossRef Medline

Igarashi KM, Ieki N, An M, Yamaguchi Y, Nagayama S, Kobayakawa K, Kobayakawa R, Tanifuji M, Sakano H, Chen WR, Mori K (2012) Parallel mitral and tufted cell pathways route distinct odor information to different targets in the olfactory cortex. J Neurosci 32:7970-7985. CrossRef Medline

Kapoor V, Provost AC, Agarwal P, Murthy VN (2016) Activation of raphe nuclei triggers rapid and distinct effects on parallel olfactory bulb output channels. Nat Neurosci 19:271-282. CrossRef Medline

Kikuta S, Fletcher ML, Homma R, Yamasoba T, Nagayama S (2013) Odorant response properties of individual neurons in an olfactory glomerular module. Neuron 77:1122-1135. CrossRef Medline

Kiyokage E, Pan YZ, Shao Z, Kobayashi K, Szabo G, Yanagawa Y, Obata K, Okano H, Toida K, Puche AC, Shipley MT (2010) Molecular identity of periglomerular and short axon cells. J Neurosci 30:1185-1196. CrossRef Medline

Kosaka K, Toida K, Aika Y, Kosaka T (1998) How simple is the organization of the olfactory glomerulus?: the heterogeneity of so-called periglomerular cells. Neurosci Res 30:101-110. CrossRef Medline

Liu S, Shipley MT (2008) Multiple conductances cooperatively regulate spontaneous bursting in mouse olfactory bulb external tufted cells. J Neurosci 28:1625-1639. CrossRef Medline

Liu S, Plachez C, Shao Z, Puche A, Shipley MT (2013) Olfactory bulb short axon cell release of GABA and dopamine produces a temporally biphasic inhibition-excitation response in external tufted cells. J Neurosci 33: 2916-2926. CrossRef Medline

Liu S, Puche AC, Shipley MT (2016) The interglomerular circuit potently inhibits olfactory bulb output neurons by both direct and indirect pathways. J Neurosci 36:9604-9617. CrossRef Medline

Mori K, Kishi K, Ojima H (1983) Distribution of dendrites of mitral, displaced mitral, tufted, and granule cells in the rabbit olfactory bulb. J Comp Neurol 219:339-355. CrossRef Medline

Nagayama S, Takahashi YK, Yoshihara Y, Mori K (2004) Mitral and tufted cells differ in the decoding manner of odor maps in the rat olfactory bulb. J Neurophysiol 91:2532-2540. CrossRef Medline

Najac M, De Saint Jan D, Reguero L, Grandes P, Charpak S (2011) Monosynaptic and polysynaptic feedforward inputs to mitral cells from olfactory sensory neurons. J Neurosci 31:8722-8729. CrossRef Medline

Najac M, Sanz Diez A, Kumar A, Benito N, Charpak S, De Saint Jan D (2015) Intraglomerular lateral inhibition promotes spike timing variability in principal neurons of the olfactory bulb. J Neurosci 35:4319-4331. CrossRef Medline

Orona E, Rainer EC, Scott JW (1984) Dendritic and axonal organization of mitral and tufted cells in the rat olfactory bulb. J Comp Neurol 226:346356. CrossRef Medline

Otazu GH, Chae H, Davis MB, Albeanu DF (2015) Cortical feedback decorrelates olfactory bulb output in awake mice. Neuron 86:1461-1477. CrossRef Medline

Padmanabhan K, Urban NN (2010) Intrinsic biophysical diversity decorrelates neuronal firing while increasing information content. Nat Neurosci 13:1276-1282. CrossRef Medline

Parrish-Aungst S, Shipley MT, Erdelyi F, Szabo G, Puche AC (2007) Quantitative analysis of neuronal diversity in the mouse olfactory bulb. J Comp Neurol 501:825-836. CrossRef Medline

Schaefer AT, Margrie TW (2007) Spatiotemporal representations in the olfactory system. Trends Neurosci 30:92-100. CrossRef Medline 
Shao Z, Puche AC, Kiyokage E, Szabo G, Shipley MT (2009) Two GABAergic intraglomerular circuits differentially regulate tonic and phasic presynaptic inhibition of olfactory nerve terminals. J Neurophysiol 101: 1988-2001. CrossRef Medline

Shao Z, Puche AC, Liu S, Shipley MT (2012) Intraglomerular inhibition shapes the strength and temporal structure of glomerular output. J Neurophysiol 108:782-793. CrossRef Medline

Shao Z, Puche AC, Shipley MT (2013) Intraglomerular inhibition maintains mitral cell response contrast across input frequencies. J Neurophysiol 110:2185-2191. CrossRef Medline

Shusterman R, Smear MC, Koulakov AA, Rinberg D (2011) Precise olfactory responses tile the sniff cycle. Nat Neurosci 14:1039-1044. CrossRef Medline

Sirotin YB, Shusterman R, Rinberg D (2015) Neural coding of perceived odor intensity $(1,2,3)$. eNeuro 2.

Smear M, Shusterman R, O’Connor R, Bozza T, Rinberg D (2011) Percep- tion of sniff phase in mouse olfaction. Nature 479:397-400. CrossRef Medline

Stockman A, Sharpe LT (2006) Into the twilight zone: the complexities of mesopic vision and luminous efficiency. Ophthalmic Physiol Opt 26:225239. CrossRef Medline

Tatti R, Bhaukaurally K, Gschwend O, Seal RP, Edwards RH, Rodriguez I, Carleton A (2014) A population of glomerular glutamatergic neurons controls sensory information transfer in the mouse olfactory bulb. Nat Commun 5:3791. CrossRef Medline

Uchida N, Poo C, Haddad R (2014) Coding and transformations in the olfactory system. Annu Rev Neurosci 37:363-385. CrossRef Medline

Vaaga CE, Westbrook GL (2016) Parallel processing of afferent olfactory sensory information. J Physiol 594:6715-6732. CrossRef Medline

Whitesell JD, Sorensen KA, Jarvie BC, Hentges ST, Schoppa NE (2013) Interglomerular lateral inhibition targeted on external tufted cells in the olfactory bulb. J Neurosci 33:1552-1563. CrossRef Medline 